\title{
A FORMAÇÃO DE MEDIADORES DE LEITURA: UMA VIVÊNCIA TEÓRICO-PRÁTICA.
}

\author{
Camila Andrea Souza de Jesus ${ }^{1}$ \\ Edilene Barbosa da Silva ${ }^{2}$ \\ Dennis Soares Leite ${ }^{3}$ \\ Robson Farias Gomes ${ }^{4}$ \\ Maria José Aviz do Rosário
}

Eixo Temático: Juventude e Educação.

Resumo: O projeto formação de mediadores de circuitos de leitura se insere em uma perspectiva que aponta o gosto e o prazer pela leitura como formas de compreensão do mundo, da palavra e da escrita e como forma de expressão da criatividade, liberdade, segurança, sonho e paixão. A partir disso, pretende, com experiências teórico-práticas, instrumentalizar mediadores para a formação de circuitos de leitura. Neste sentido, este trabalho objetiva apresentar a experiência obtida em um minicurso de formação de Mediadores de Leitura, realizado na Universidade Federal do Pará, durante três dias do mês de novembro de 2015. As metodologias utilizadas no curso foram: exposição dialogada sobre conceitos de autores como Paulo Freire e Bortolin, que apresentam o mediador de leitura como aquele indivíduo que aproxima o leitor do texto, ou seja, a ponte que os interliga; além de debates; dinâmicas; mesa redonda, mesa de relatos de experiência, exposição sobre a obra "Menina bonita do laço de fita" de Ana Maria Machado, e "O menino que queria voar" de Indigo, além de apresentação teatral no último dia de curso. Por fim, foram formadas sete pessoas, entre elas, três discentes de Pedagogia, três de Letras e um discente do Ensino Médio da rede pública do Estado.

Palavras-chave: Formação. Mediadores de Leitura.

\footnotetext{
${ }^{1}$ Discente de Pedagogia, camilapcs@yahoo.com, Universidade Federal do Pará (UFPA), Bolsista do Programa Conexões de Saberes. Proex UFPA.

${ }^{2}$ Discente de Pedagogia, Universidade Federal do Pará (UFPA), Bolsista do Programa Conexões de Saberes. Proex UFPA.

${ }^{3}$ Discente de Fisioterapia, Universidade Federal do Pará (UFPA), Bolsista do Programa Conexões de Saberes. Proex UFPA.

${ }^{4}$ Discente de Filosofia, Universidade Federal do Pará (UFPA), Bolsista do Programa Conexões de Saberes. Proex UFPA.

${ }^{5}$ Doutora em Educação, mrosario@ufpa.br, Professora da Universidade Federal do Pará (UFPA), Coordenadora do Programa Conexões de Saberes
} 
Abstract: The project formation of mediators in reading circuits is part of a perspective that shows the taste and the pleasure of reading as ways of understanding the world, word and writing and as a form of expression of creativity, freedom, security, dream and passion. From this, it is intended, with theoretical and practical experience, instrumentalize mediators for the formation of reading circuits. Thus, this study aims to present the experience in a short course of Reading Mediators training, held at the Federal University of Pará, for three days of November 2015. The methodologies used in the course were: dialogued exposition of authors concepts as Paulo Freire and Bortolin, which presented the read mediator as the individual who approaches the reader to the text, in other words, the bridge that interconnects; and debates; dynamics; round table, table experience reports, exposition of the works Menina Bonita do Laço de Fita of Ana Maria Machado and O Menino que queria voar, of Indigo, and theatrical presentation on the last day of the course. Finally, seven people were formed, including three students of Pedagogy, three of Letters and a high school student from a public state school.

Keywords: Training. Reading mediators.

\section{CONTEXTO}

O minicurso de formação de Mediadores de Leitura foi elaborado para ser submetido à Jornada de Extensão Universitária, que é um evento realizado pela Próreitoria de Extensão da Universidade Federal do Pará, sendo aprovado e realizado nos dias, 10, 11 e 12 de novembro de 2015 no Instituto de Ciências da EducaçãoICED/UFPA. O minicurso objetivou instrumentalizar mediadores de leitura, oferecendo bases teóricas e práticas para o desenvolvimento de leituras com o intuito de fomentar possíveis estratégias para despertar o gosto e o prazer pelo ato de ler.

\section{DESCRIÇÃO DA EXPERIÊNCIA}

Com o objetivo de instrumentalizar mediadores para formação de circuitos de leitura, com propostas que orientem, auxiliem e despertem o gosto e o prazer pela leitura, foram trabalhadas diversas metodologias, entre elas, exposição dialogada sobre os conceitos de autores como Paulo Freire e Bortolin que apresentam o Mediador de leitura como aquele indivíduo que facilita a relação entre leitor ou futuro leitor e texto (FREIRE, 1989). 
Mediador é definido como aquele indivíduo que aproxima o leitor do texto. Em outras palavras, o mediador é o facilitador desta relação. E como intermediário de leitura, o mediador encontra-se em uma situação privilegiada, pois tem nas mãos a possibilidade de levar o leitor a infinitas descobertas. (BORTOLIN, 2007, p. 1).

Após o debate sobre o conceito de mediador, discutimos sobre os diferentes tipos de mediadores, haja vista que durante a vida o indivíduo pode ter intervenção de diversos sujeitos que o aproxime ou estimule ao ato da leitura. Como Bortolin (2007, p. 1), cita: "Os familiares, os professores, os bibliotecários, os escritores, os editores, os críticos literários, os jornalistas, os livreiros, os tradutores, e até os amigos que nos emprestam um livro ou indicam." Desta forma, compreendemos que mediar a leitura, não é papel apenas dos professores ou pais, apesar de Bortolin classifica-los como fundamentais, mas de toda e qualquer pessoa que se disponha para tal, desde que queira auxiliar alguém a aproximar-se de alguma maneira à leitura.

Ainda com exposição dialogada e também ainda referente aos teóricos já citados, apresentamos pontos referentes à importância da leitura para a formação do cidadão, formação do leitor, diferença entre mediador de leitura e contador de história, e métodos e técnicas possíveis para despertar o interesse à leitura, utilizamos também debates sobre experiências dos participantes do minicurso e seus primeiros mediadores de leitura, além de apresentação de obras como; "A menina bonita do laço de fita" de Ana Maria Machado, que retrata a admiração de um coelhinho branco por uma menina negra, oportunizando um debate sobre racismo e respeito a diversidade; e a obra " $\mathrm{O}$ menino que queria voar", de Indigo, tratando sobre a vida de Leonardo da Vinci, de sua obsessão pela natureza e em desmembrar suas estruturas elementares, bem como de seu distanciamento dos ensinamentos religiosos mais convencionais. Dentre estas, os participantes tiveram que escolher uma, para apresentar/contar no último dia do minicurso, adotando a contação de história como ferramenta para a mediação da leitura. 


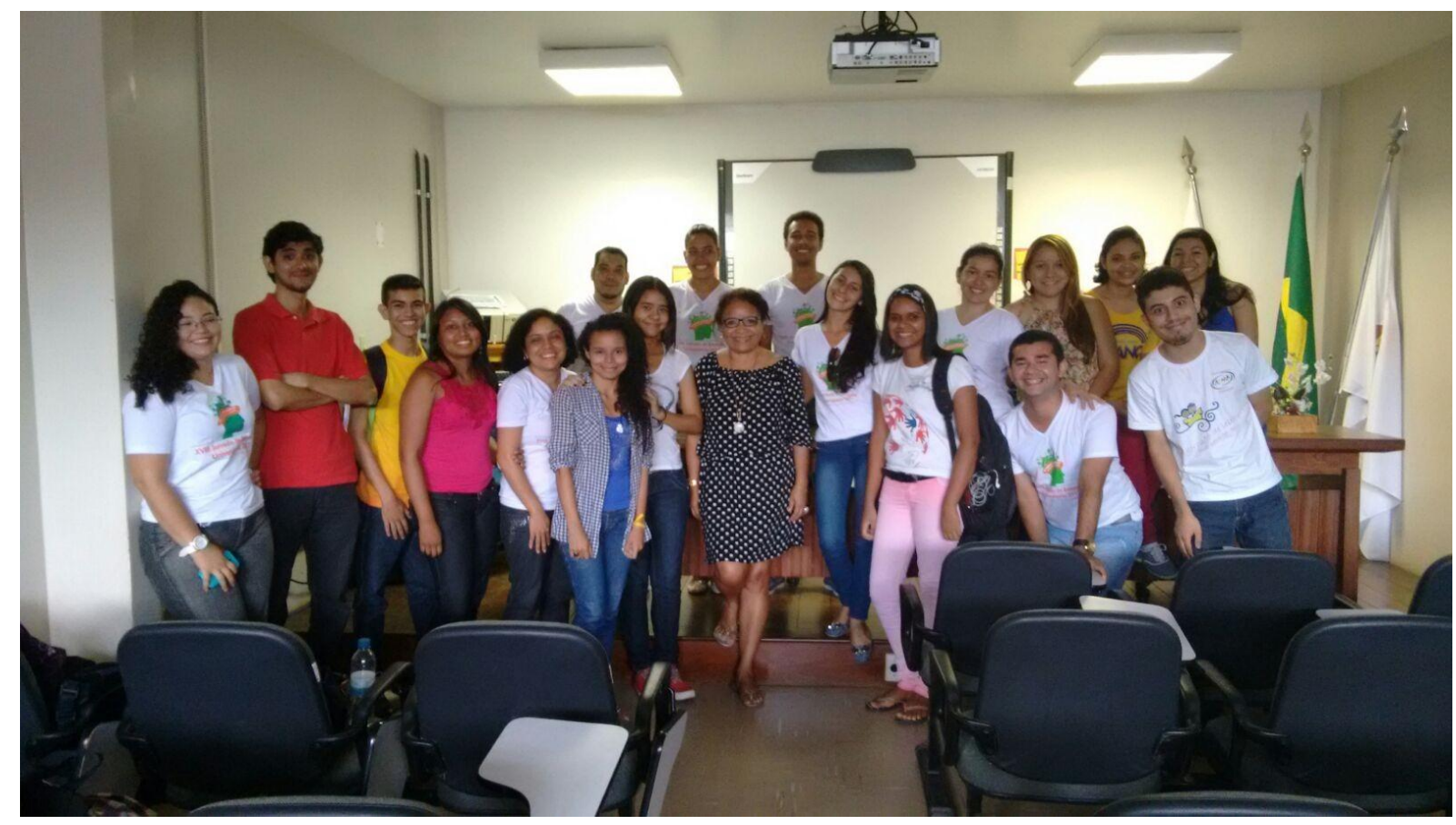

Figura 1: Primeiro dia de Minicurso, com os organizadores e participantes.

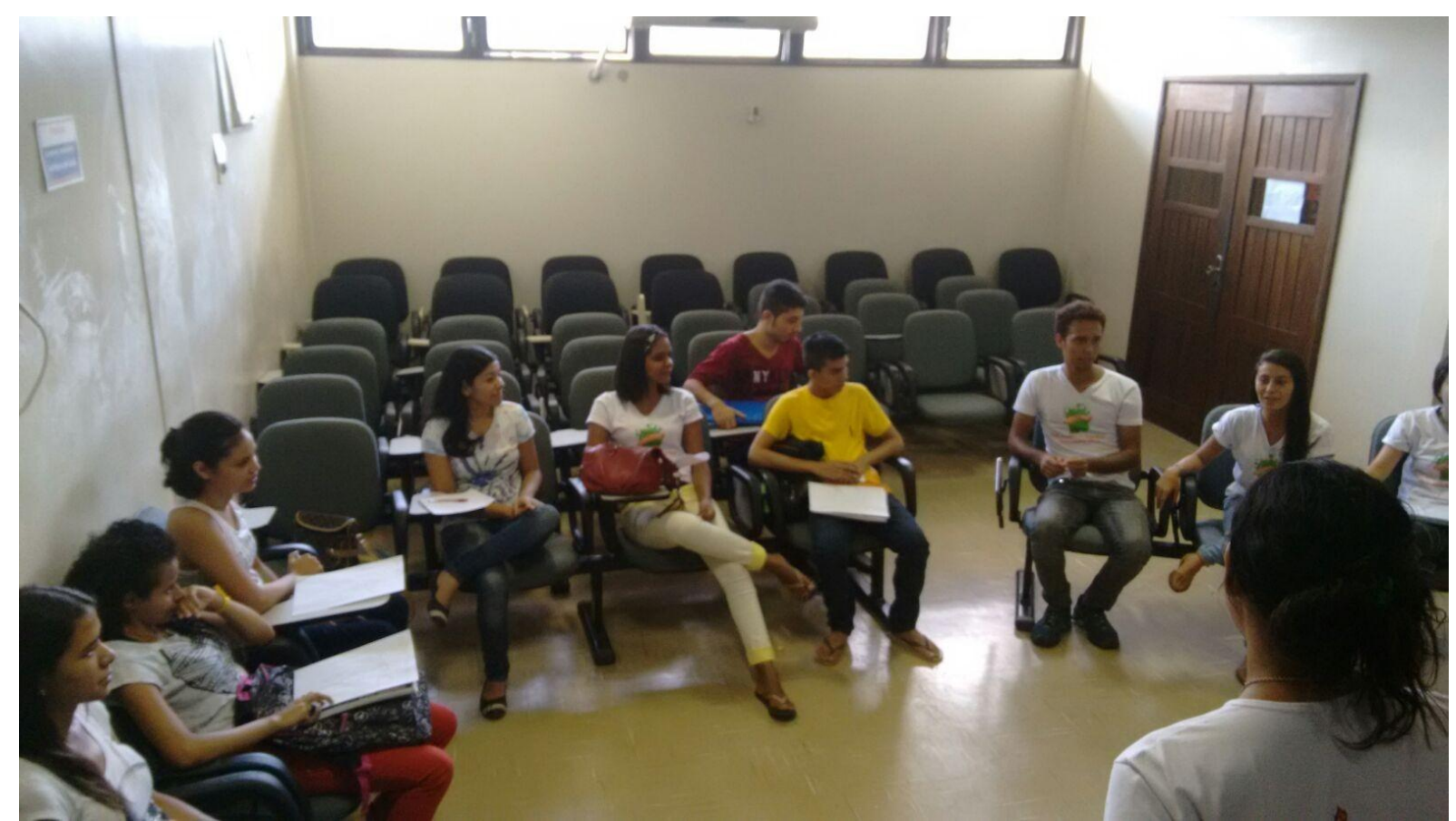

Figura 2: Roda de conversa - segundo dia de minicurso 


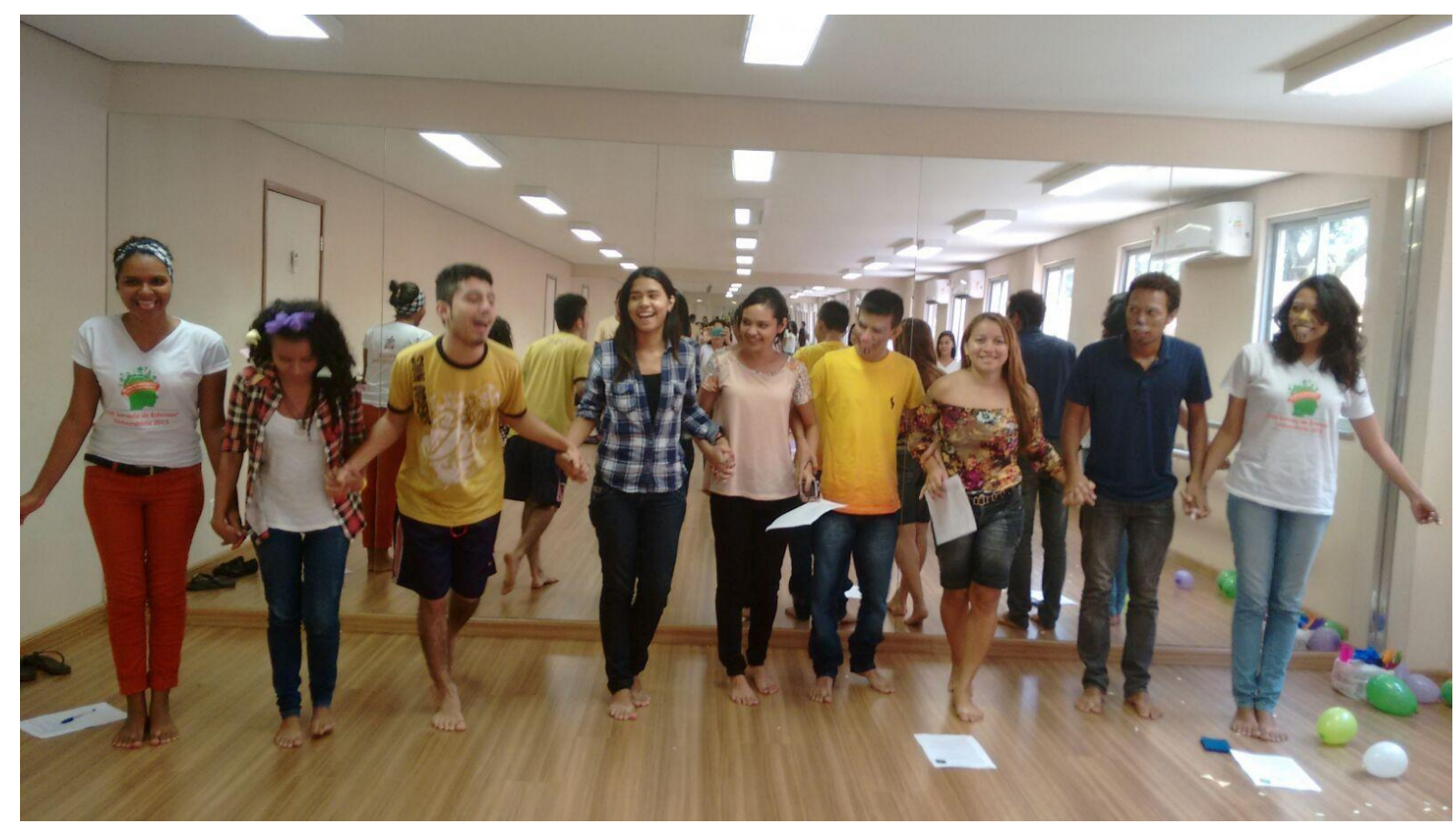

Figura 3: Apresentação teatral da obra A menina bonita do laço de fita, de Ana Maria Machado. - Último dia de minicurso.

\section{RESULTADOS}

No desenvolvimento do curso de mediadores de leitura, tivemos resultados muito positivos, pois conseguimos apresentar e dialogar sobre os conceitos defendidos por autores como Paulo Freire e Bortolin, além de teorias defendidas por Ziraldo, o qual concebe a leitura, não como algo que precisa ser imposto, mas como algo que precisa ser desenvolvido para além da obrigação, e assim, para o desenvolvimento do verdadeiro interesse, gosto e prazer. Ademais, conseguimos sensibilizar os participantes para refletirem sobre a importância do mediador de leitura, além de conseguir apresentar possíveis ferramentas para aproximar o texto do leitor e despertar o prazer pelo ato de ler. Por fim, realizamos a formação de sete pessoas, entre elas, três discentes de Pedagogia, três de Letras e um estudante do Ensino Médio da rede pública do Estado.

\section{REFERÊNCIAS:}

BARBOSA, J. B. A mediação: reflexões sobre a formação do professor. Mercado de Letras. Campinas, ed. 1. 2013.

BORTOLIN, S. O Mediador de leitura. 2007. Disponível em: <http://www.ofaj.com.br/colunas_conteudo.php?cod=302> Acesso em: 14 de janeiro de 2016. 
FREIRE, Paulo. A importância do ato de ler: em três artigos que se completam. 23. ed. São Paulo: Cortez, 1989.

MORAES, Fabiano. Contar Histórias: a arte de brincar com as palavras. São Paulo: Vozes, 2012. 124 p. 